DOI: $10.1515 /$ hssr -2016-0025

\title{
Thinking Poverty: Basic Codes
}

\author{
Ivan Katzarski
}

Bulgarian Academy of Sciences, Sofia, Bulgaria

\begin{abstract}
The present-day viewing of poverty in a predominantly economic perspective is neither "natural", nor self-evident, nor the only possible viewpoint. The perception of poverty is always part of an integral worldview (Weltanschaunng). This article aims to shed more light on some elements (basic codes) of a somewhat unconscious construction of the world, which predetermine various views on poverty in different societies and civilizations. Here the codes are thought of as the most general ways and modes of perception of social reality, and general strategies of behavior within that reality. These codes characterize the specific stances of practical subjects (individuals, groups or larger communities), stances that represent an alloy of perception and action. Two types of codes are distinguished: structural and formative (cultural, civilizational). The structural codes are only two in number: the dual and the hierarchic, while the formative specifically characterize an individual culture or civilization. The different types are reconstructed with reference to a number of historical studies. Among the formative codes, special attention is devoted to those specific for the Judaic, Christian, and Islamic civilizations.
\end{abstract}

Keywords

Poverty, Basic codes - structural (dual, hierarchic) and formative (civilizational), Judaism, Christianity, Islam.

\footnotetext{
* Institute for the Study of Societies and Knowledge at the Bulgarian Academy of Sciences, 13A, Moskovska str. 1000 Sofia, Bulgaria; email: pessoko@gmail.com
} 


\section{Introduction}

In contemporary societies, poverty is presented primarily in economic terms: people are poor when they lack income and are deprived of basic resources for survival (food, clothing, housing). This condition is not only a threat to their physical existence but is a factor of social degradation and marginalization.

However, numerous essays, some of which I shall refer to in the following analysis, have shown that the contemporary predominantly economic view on poverty is neither "natural", nor self-evident, nor the only possible one. In fact, in this aspect, poverty is not at all a one-of-akind phenomenon: in the world of humans, there are no "natural" and absolutely objective things; what we know about the world is always mediated by the activity of a certain subject. This might be Kant's transcendental subject or a subject in some more concrete quality.

The perception of poverty is always part of some integral worldview (Weltanschauung). The fact that people of a given society or culture are usually inclined to think of poverty as something self-evident, and comprehensible in itself, only means that their own way of perceiving reality has become habitual for them; it has become an element of a social or cultural unconscious.

This article aims to shed more light on those elements of the unconscious construction of the world that predetermine various views on poverty in different societies and civilizations. As I will try to argue, this does not refer merely to a perception, or knowledge, of reality but to a vision which is simultaneously an instruction for action. My search goes in the direction of what Peter Brown defines as the "aesthetic of society" or the "imagination of society" (Brown, 2005). These terms, however, seem to me to be rather indefinite and intuitive. My aim is to lean on empirical studies in order to achieve a better-defined and more structured conceptualization.

In accordance with the approach followed here, the interpretation of the phenomenon of poverty should be pursued at three structural levels - basic codes, world views, and history. Here, my chief focus is on codes, which are the most fundamental elements and the hardest to identify and understand. They predetermine the deepest socially constructed and civilizational differences. More than one worldview may 
be formed on the basis of the same code, and these views, in turn, characterize the basic periods of historical development of a given civilization. The most concrete and rich in substance is the third level that of history. On the one hand, it represents a complex interaction of demographic, technological, economic, political and cultural processes, which serve as an objective basis for the choice of possible, or invention of new, interpretative codes and worldviews. On the other hand, these codes and views are both cognitive and practical responses of active subjects (social groups or whole societies) to various historical challenges. The codes themselves may combine or overlap, generating complex worldviews and historical realities.

So far, all this is quite abstract. It will acquire meaning only in the context of the following, more concrete analysis.

\section{Structural codes}

In this text, codes are thought of as the most general ways or modes of perception of social reality and strategies of conduct in that reality. As I pointed out, they characterize the specific stance of practical subjects (individuals, groups or larger communities), which is an alloy of perception and action.

Here, I distinguish between two types of basic codes. The first type I designate as structural codes; each of these characterizes some large group of societies and claims, to a considerable degree, to be universal. The second type of codes I define as formative, individualizing, or specifying, with respect to a single culture or civilization (or, briefly, formative, individualizing, specifying, cultural, civilizational). The distinction between these two types is fundamental and yet somewhat relative: each structural code predetermines a more or less elaborate, integral worldview and also shapes the appearance of most of the cultures and civilizations known to us, while every cultural or civilizational code predetermines some kind of structuring of social reality. But the aspect and meaning of the distinction introduced here are essential.

The structural codes are connected to the components of a social whole (a society) and, respectively, to the boundaries within that whole. In the world of nature and in the world of ideas, there are integral 
wholes that consist of various numbers of parts (elements) and have various structures and forms of organization. In a purely objective aspect, societies may be viewed in the same way: as more or less complex wholes, in which one kind of organization is real and valid no less than every other kind. But things appear quite different from the position of social subjects (individuals and groups). They encode reality, schematize it, which inevitably leads to a great simplification of that reality. This proves to be an important precondition for the formation of a behavior strategy in a world that is, in itself, quite complicated.

The structural coding of social reality attains a degree of simplification at which it is possible to refer to two most basic codes, which here I conditionally call "dual" and "hierarchic". The dual code may in some cases contain an element of subordination as well, but that does not make it typically hierarchic; the latter type would require the presence of more than two parts or elements in a single whole.

What are these codes and how are they relevant to the phenomenon of poverty? Dual codes break up social reality and serve as the basis for the distinction between "our own" and "strangers", between the members and the non-members of a given community (clan, tribe, estate, caste, commune, etc.). The basic characteristic of these communities is solidarity. It extends only to the members, while non-members are excluded. The needy, that is, the people whose physical existence and social status are at risk, do not fit into such boundaries, they are both within the respective community and outside it. Nevertheless, the dual code (belonging and not belonging) distinguishes them sharply: they receive attention and care from the community not because they are poor but because they are part of it; towards all other persons, the attitude is one of indifference, purely instrumental, or hostile.

Countless examples of such relations could be adduced. Peter Brown describes a particular structuring of social space in the cities of Ancient Greece and Rome before Christianity became the official religion. Being a citizen of the polis generates rights and duties that define a privileged status, of which non-citizens are deprived. Citizenship, however, does not in itself guarantee wealth. The plebeians of Rome, for instance, were quite poor, but they were treated differently from the mass of poor noncitizens of Rome. The polis, as well as individual philanthropists, helped 
the poor, but they did so only because, and insofar as, the latter were part of the polis, that is, had the quality of fellow citizens. The other poor did not figure as objects of public or private charity (Brown, 2002: 3-5; see also: Wjuniski and Fernández, 2009: 803).

Such a dual structuring is far from exceptional. In a typical medieval community or guild, full membership meant "participating in a group, being known, having a public role, pursuing mutual goals" (Clark, 1994: 385). Inner contradictions and conflicts were alleviated "through traditional ceremonies of communion and exchange. Banquets and communal meals promoted harmony and goodwill but also provided an occasion for the many to judge the misconduct of the few" (Clark, 1994: 385-386).

Neediness is the constant companion of the rural community, and the only effective strategy against it is solidarity. When some member of the community is no longer able to care for him/herself due to old age or illness, he/she must find some caretaker in the person of a relative, friend or some other member of the community. This caretaker becomes a user of the land of the person cared for, and has the right to income from that land, under the sole condition that he provide what is necessary (in terms of shelter, food, clothing) to the person cared for. In addition to the rights, the caretaker also assumes the duties to the lord, including the payment of rent. Orphans, as heirs to full members of the community, are treated similarly. In addition, the guardianship exercised over them is under the control of the entire community, which serves as a guarantee against possible abuses (Clark, 1994: 389-393).

This, however, is only one category of poor people - members of the community who have fallen into trouble and can rely on the support of "their own people". Together with them, there is a category of poor that the members of the community treat in a purely instrumental way, rejecting and despising them. These are, foremost, the lepers. Because of their terrible disease, they are deprived of inheritance and of all other rights, are forced to stay away from the community and be isolated; they are the "living dead". However, as Clark points out, "the plight of lepers paralleled the regulation of strangers and itinerant laborers in various ways. Neither vagrants nor lepers shared the public life of the countryside but together suffered from a certain placelessness". They 
raised mistrust, because they were "masterless" folk. Allowed to enter the outskirts of the village, they were the target of constant suspicion on the part of the peasants and the authorities; they were suspected of being "dishonest", "faithless", "rebels". "All certainly were poor and economically vulnerable to seasonal shifts in employment." But in a positive sense, the community was interested in them only insofar as it could use them as hired workers at harvest time (Clark, 1994: 397-398).

Medieval guilds are another example. Their members were not equal in economic status and formal power. There was an elite among them which strove to monopolize decision making and to preserve its exclusive standing. At the same time, however, the guilds are a kind of fraternity which shares common values, is united by common interests, and counterposes the members of one guild to all others and to the surrounding social universe in general. A special aspect of this relationship is that masters from all guilds oppose as a whole all those who are not guild members and are in a subordinate position with respect to the masters, i.e., the apprentices, journeymen, day-labourers (see, for instance: Kaplan, 1986: 631-632). We find that the guild, as institution, could radically change the lives of some women. In general, widowhood was a severe blow to the wives of peasants and artisans. But the widows of guild masters in Paris had the right to inherit the title of master from their husbands and to manage a workshop in their own name. Thus, entry into the man's world of the corporation largely ensured them a high status and prosperity (Lanza, 2009: 94).

An even more salient example of dual relationship of inclusionexclusion is provided by castes, with their internal solidarity and the opposition between higher castes and the dalits (untouchables). The latter group occupied the absolute bottom of society. It suffered economic deprivation, social exclusion, and a life of humiliation. They were the "impure", and contact with them (even a mere glance) represented "pollution" and required ritual purification. They were allotted the "impure" occupations and were segregated within the village or city (see, for instance: Sahai, 2005: 529-535; Jodhka and Shah, 2010).

The Chinese lineage organizations are another example of strong internal solidarity extending exclusively to group members. These organizations established funds for the maintenance of charity schools 
for children of their own community, which opened the possibility for members of the kinship group to occupy high-rank state positions. They were also active in providing material assistance for the sick, widows, orphans, the poor, the unemployed. Of course, non-members were excluded from all these benefits (Handlin Smith, 1987: 310).

The dual code is reproduced in a specific way in contemporary societies. "We are all familiar with the modern city - the symbol of affluence, the well-planned roads, golf fields, parks, markets, the created system of large spaces, the office towers, and the residential skyscrapers. Nestling cheek by jowl with these symbols of the affluent are the neighbourhoods of the urban poor - those spaces which people who are sought to be excluded from the gains of development have constructed for themselves. These shantytowns - jhuggi jhopries, favelas, bastis, barrios - are the assertion of an excluded section of the people in a spatial arena which was not planned for them by the dominant classes but which they have constructed on their own" (Chandhoke, 1989: 112).

The city of the wealthy is a center of activity of many formal organizations (state institutions, municipalities, firms, non-governmental organizations). Capital and bureaucracy are dominant here, while personal relationships and solidarity play a very minor role. In this city, there are also some very poor people, but they manage to maintain a minimal standard with respect to the official culture. The city of the poor, as Chandhoke has shown, is in complete contrast, and not only in its outward appearance. In it, people survive thanks to their personal interconnectedness and mutual solidarity. Not all are poor and weak in that world, there are some wealthy and powerful people there, who form a local elite. This elite regulates relations - to a great extent based on the principle of clientelism - and is in contact with the official authorities and other organizations. The city of the poor reproduces pre-modern relationships, although it is a typically modern phenomenon (Chandhoke, 1989: 113-114).

The dual code is based on alternativeness: it includes some individuals and groups only because it excludes others. To the contrary, the hierarchic code is inclusive. It forms an integral whole comprising heterogeneous elements characterized by coordinated functioning, and subordinated to a common logic. This implies the presence of a 
governing center which sets the rules and controls the behavior of the separate parts of the whole. In society, such a center is a group or institution, often headed by a single person.

Internally, relatively simple forms, such as the clan, the guild, the caste, the commune, etc., represent more or less developed hierarchies. In the age of written history, however, there is usually a state structure rising above them, which has different complexity and degrees of development in different societies, and which, in turn, is also hierarchic in organization. The hierarchic code is the code of domination and subordination. It is on its basis that ideas about the cosmic and social order arise, some of which strive to justify and strengthen domination, while others question its legitimacy and strive to reject it. The former ideas are those of the official ideology, the latter are those of the radical opponents of the status quo.

Being an autonomous subject, the state is able to implement its own strategy or policy towards the poor. But the degree of autonomy of this policy depends not only on the state's own initiative but also on numerous objective circumstances, including the correlation of power between the state and the social groups it controls. The state policy may simply be a tool for maintaining the already established relationships, in which the poor are distinctly separated into "inner" and "outer" (by force of the dual code) and, respectively, are treated differently. The attitude of state formations towards castes, and particularly towards the dalits, in the traditional societies of India and some other countries can probably be best construed within this perspective. In post-colonial India, however, the state becomes an active factor for surmounting caste differences and especially for raising the status of the dalits. In Pakistan, Sri Lanka and Nepal, however, even the modern state does not pursue such an active policy, and remains "blind" to caste hierarchies, while not officially recognizing the existence of castes (Jodhka and Shah, 2010: 106).

In most societies in which a state has existed, it shows itself to be an independent and active factor of social policy. The states in the ancient world, such as the Greek polises, Rome (the Republic and the Empire), Egypt, Persia, and some other monarchies, "established programs of public philanthropy by means of which surplus foods were periodically 
distributed to the poor" (Jodhka and Shah, 2010: 146). In the states of the ancient Middle East, the King was the main center and source of charity; "it was he, who took care of the disadvantaged part of the population". Together with victories over external enemies and the construction of temples, this care became "a main topic of royal propaganda" (Lohfink, 1991: 35).

In Islamic culture, there were two established forms of charity, based on the decrees set down in the Qur'an. The first of these forms is the zakat, the obligatory alms tax, which is collected from all Muslims who possess property or income above a certain minimum. The second form of charity, the sadaqua, consists in voluntary donations, which it is recommended all Muslims should make in proportion to their material situation (Singer, 2005: 482). It is important to stress that mandatory payments for charitable purposes, first established by the Prophet Muhammad, incited a revolt among some Arab tribes, and was firmly asserted only after resistance was crushed (Bonner, 2005: 394).

The Chinese imperial tradition was quite different. "Until at least the eleventh century, acts of charity to the poor ranked low in the hierarchy of official values, dismissed as 'little acts' and endowed with little public resonance. They were overshadowed by a robust state ideology of responsibility for famine relief, which put its trust, not on anything as frail as 'compassion,' but on great state warehouses controlled (it was hoped) by public-spirited provincial governors" (Brown, 2005: 517-518). In fact, the activity of the state was aimed not at direct assistance of those poor who had already fallen in status, but at the protection of those who, although at risk and in need, continued to be part of the working economic structure. They were protected, for example, through a price control policy involving the accumulation of state provisions (chiefly of rice) in years of plenty, and freeing these provisions on the market in years of shortage. Another tool was the loaning of seed for sowing to farmers during the spring on condition that they return that amount of seed in the autumn, after the harvest (Florence, 2010: 29-30).

However, those standing at the very bottom were segregated and repressed by the state. While the state created and maintained charitable institutions for orphans, cripples, the blind, the aged (Handlin Smith, 1987: 310), it enslaved criminals and beggars (Vassil'ev, 1998: 245-249). 
According to Brown, this policy was mitigated under the influence of the Buddhist idea of "compassion" (Brown, 2005: 517-518). In 1780-1750, private charity developed considerably (Handlin Smith, 1987).

We see that a very interesting development took place in Christian Europe. Starting from the period when Christianity was imposed as the official religion and until the middle of the $14^{\text {th }}$ century, the state was rather passive and practically had no policy of its own with respect to the poor; kings and high-ranking dignitaries, acting as sponsors, were more or less generous in supplying resources to the Church, which assumed the responsibility of caring for the poor. The Church acquired a monopoly on public charity. This tradition had begun with the Roman emperors, who had entrusted the Church with donor funds (Bird, 1982: 163).

A significant change occurred towards the middle of the 14th century in connection with the Black Death epidemic, which killed at least one third of the European population and brought about a shortage of labor force. Wages grew high and workers found themselves in an advantaged position. Then the state intervened and enacted Poor Laws, first in England and France. The Protestant Reformation gave new impetus to legislation regarding the poor, which acquired its classical form. Moreover, these laws were similar in type in Catholic and Protestant societies and there were no significant differences among them. The laws sanctioned the distinction, already established in society, between the deserving and undeserving poor. The former group encompassed those who were undoubtedly weak (widows, orphans, the blind, invalids, lepers, aged people) and could not rely on the support of relatives or the community. They were the only ones who had the acknowledged right to social care. The latter group consisted of people of degraded social position (vagrants, beggars), who were considered healthy and able to work. They were perceived as harmful and dangerous elements in society and were amenable not only to moral censure but to severe disciplinary measures, such as expulsion from settlements, corporal punishment, isolation in reformatory institutions or penal colonies (Walter, 1973: 249253; McIntosh, 2005; Pullan, 2005: 443-444, 447-450). Under Western influence, in the $19^{\text {th }}$ century, this model was copied in other societies as well, for instance, in Egypt and the Ottoman Empire (Ener, 2005). 
In their classification of the poor, and in their attitude towards them, Western Christian societies from the middle of the $14^{\text {th }}$ to the end of the $19^{\text {th }}$ century were similar in no small degree to the Chinese state tradition. But they showed at least two important differences compared with China. In Europe, in the period in question, there was no policy at all similar to the Chinese state economic policy aimed at assisting the welfare of the economically active poor strata through control of prices and by other methods. Insofar as they set themselves the goal of assisting the deserving poor, European states did not use the instruments of centralized taxation: they mainly charged local structures (cities, parishes) with the task of funding and organizing assistance to the poor. Moreover, the very philosophy and instruments of the Poor Laws were initially elaborated in urban practice (McIntosh, 2005: 458-459).

As is well known, at the end of the $19^{\text {th }}$ century, at various speeds in various countries, a decisive turnabout took place in state policy. The attitude towards poverty changed in principle: it was construed no longer in terms of moral categories but as a phenomenon linked to objective economic processes. It was now asserted that only the state is capable of dealing with poverty, and hence it was obliged to undertake the solution of this problem. Centralized taxation now became the resource by which to achieve this goal. The national states undertook to pass laws for the protection of women's and child labor, for health and retirement insurance, and for providing assistance to groups at risk (Woodard, 1962: 287-289).

Today, the direction of development is again different. Since the 1970s, the welfare state has been in a state of crisis; it is shrinking, while the forces and ideology of the market have gotten the upper hand. At the same time, poverty has gained new territories, and unlike the situation in the $19^{\text {th }}$ century, it is no longer a problem of separate nations but a global one. Today's severe crisis related to the migrant waves in Europe is only the acute phase of a larger chronic problem: in a globalized world, following the logic of communicating vessels, the poor cannot be apprehended and isolated on some sad continents and islands of misery and insecurity. They will inevitably press and spill over into the world of prosperity and security, although they can hardly become a genuine part of it. If for no other reason than their own future interest, Western 
societies today require bold and innovative responses to urgent problems. In order to find the right answers, they need to rethink not only their own historical experience but the experience of other societies and civilizations as well.

Of interest in this connection are some other types of codes, different from the structural ones that we have conditionally called formative (cultural, civilizational). While structural codes are only two in number, the dual and the hierarchic, each of which characterizes the social perception and behavior of individuals and groups in most of the known societies, the formative codes are numerous, and each of them is strictly specific to a definite culture or civilization. They will be discussed in the following section. But before that, I find it necessary to give a brief account on the issue to what extent the dual and hierarchic code truly exhaust the class of structural codes.

The dual code defines a polarization; and the hierarchic one, a subordinated structure of society. We can easily imagine units that are neither dual nor hierarchic in their mutual connection but interact nevertheless. However, within social reality, these units would be autonomous societies that are in external relations with one another and hence do not form a dual or hierarchic structure. Various kinds of relationships may exist between such autonomous societies, depending on the concrete circumstances. They may cooperate in certain areas, they may compete, or they may be at war with one another. When I assert that the dual and hierarchic codes exhaust the class of structural codes, I have in mind only the structuring that concerns the internal organization of a single society.

For the sake of completeness, I would like to examine a borderline case of social organization that is also relevant to the issue of solidarity with people who, for some reason, are in a disadvantaged situation.

I mean societies like !Kung and Hadza, excellently described by Woodburn (1982: 1998). In them there is no dual exclusion and opposition, and their hierarchy approximates zero. These are band societies, usually numbering between ten and thirty people. The men are mostly occupied with hunting, and the women, with gathering. What is common to these groups is that they live in an extremely unfavorable natural environment, which only partially, however, determines their 
specific organization; essential to them is what may be called their cultural code. These are groups with a highly indeterminate territorial location and group composition: a band has no permanent territory and is constantly open - some leave and others join it. It is noteworthy that lepers are not excluded, though all members are perfectly aware of the risk of contagion. Starting from a comparatively early age, each individual provides for himself, gets food on his own, and men are capable of defending themselves. Cooperation is not excluded, but is always an act of free self-determination, and is only limited to separate undertakings, i.e., is situational and short-lived. Even in the framework of the family, there is a faint resemblance to a household: spouses and, from an early age, children provide their own food and consume it separately without regard for one another. What elements of hierarchy might appear are founded only on moral authority and are not connected in any way with property relations or formal hierarchy. Each person guards his personal autonomy as a precious thing.

In such fluid societies, one observes a strange combination of a low degree of cooperative action and a leveling distribution of surplus goods. This occurs in an economy which, under the force of social norms, excludes the possibility of stocking up with provisions and of postponed consumption, although these are objectively possible even in that very unfavorable natural environment. Neither individual nor the group amasses surplus provisions. When a large animal is killed or more vegetable food is acquired, it is divided and consumed by all almost immediately. If a luxury item is acquired by one member of the group, it does not become his exclusive property but constantly changes its owner on the basis of a specific form of gambling. Yet, this form of redistribution can hardly be defined as solidarity. Each member of the band considers it the norm that he has a rightful claim to a share of the surplus or the luxury item; but this can hardly be said to represent some kind of mutual commitment or solidarity. Cases are known when seriously ill members have been abandoned when unable to care for themselves. The attitude towards those suffering from leprosy is particularly indicative: true, the group admits them, but within the group they are a target of cruel ridicule. This lack of compassion and commitment is quite understandable in view of the dominant cultural 
norms: "The potentiality for autonomy and the limitation of obligations to specific other people - as opposed to the generalised obligation to share - certainly seem to reduce the sense of commitment that people feel to others (...)" (Woodburn, 1982: 448, italics in the text).

The organization of band societies may be defined as quite archaic. Paradoxically, similar tendencies can be found in modern societies that emphasize the autonomy of the individual. At the same time, there is an openness and tolerance towards others, those who are different, but also a coolness of personal ties and community solidarity. The similarities with modern societies, however, end here, because the latter are based on a very developed form of private property and do not at all tolerate leveling distribution. Moreover, personal autonomy in them is only one aspect of relations; it is significantly limited by economic and bureaucratic power.

Apart from societies of the !Kung and Hadza type, I cannot point out any others for which the dual and hierarchic codes might not apply. It is another matter that some organizations may be considered nonhierarchic when they meet some very specific conditions (see, for instance: O’Neill, 1982; Niman, 2011). This is possible in principle, because organizations, especially modern ones, unlike societies, are devoted to some specific goals, and the individuals do not exist in them as complete beings but only by some single aspect of their being. Here, I am discussing societies, not organizations.

\section{Formative (cultural, civilizational) codes}

!Kung and Hadza are, in a way, cosmopolitan societies. The structural codes of duality and hierarchy are not operative in their social organization. However, the social vision and practice is determined by a basic code that can be presented through the following key definitions: a high degree of autonomy of individuals and a relatively weak commitment to a human group, place, or specific individuals; immediate consumption that excludes accumulating provisions; each person having a share of the surplus, so that dependencies of someone or on someone are not formed. In this situation, there can be no poverty in the proper sense: from an early age, each member must be able to obtain his own food, while individual abilities or random circumstances give them no 
advantages in terms of wealth or power.

Here, I conditionally call this cultural code formative, or individualizing. The most fundamental principles of social order are established through it (what Peter Brown calls the "esthetics of society"). In this case, the code is a reconstruction drawn from concrete practices.

Below, I will discuss other formative (civilizational) codes found in sacred texts, specifically, in the holy books of Judaism, Christianity, and Islam. In these cases, the cultural codes might even be called "metaphysical", because they directly link the principles of social order to the principles of cosmic order. Postulated as underlying all is God as the absolute initial and formative principle. Despite this premise common to the three religions, I believe there is reason to assert the existence of three different civilizational codes, which shape different social visions and practices, including society's ways of thinking of, and strategies of coping with, poverty.

How should the formative (civilizational) code of Judaism be read?

The literary monuments of the ancient Near East (Egypt, Babylonia, the Hittites, the Canaanites) are distinguished by their emphatic attention and care for the weak and poor. The Jewish Bible is no exception: "Nearly every motif, even the words, seemed to be part of a common heritage" (Lohfink 1991: 35). However, there is a very significant difference: the rulers of the region are the centers from which the resources and initiatives for charitable activities came. The rulers make donations, cancel debts at times, etc. Yet, in the law texts themselves, poverty is not articulated as a problem - the "poor" and "oppressed" are given attention only in the prologues and epilogues of the respective codes of law. In other words, they are present only in the ideological framework of the laws. In the Bible, however, poverty becomes a central issue of the law itself: "even in the oldest biblical law code, the poor are no longer excluded from the laws proper" (Lohfink 1991: 37-38).

Even more importantly, this is not an ordinary law, established by man, but a law sealed by divine authority. The Torah ordains that the attitude towards the poor be the same as God's attitude towards the people of Israel: He saved them from persecution in Egypt, gave them food in the desert, "and he included them into himself in a covenantal relationship" (Hussain, 2008-2009: 129). Similarly, the people of Israel 
must look after the needy and the weak, who are part of it: to protect them from "harm and injustice, provide for their basic necessities, or include them in community" (Hussain, 2008-2009: 108). When treated unjustly, the widow, the orphan, the needy person may send their "cry of distress" to God in order to gain His protection. This cry "rouses the anger of God against the offending party, to whom God says, 'Then I will kill you with the sword so your wives will be widows and your sons will be orphans"” (Hussain, 2008-2009: 109).

These biblical texts refer to a pre-state condition of society. The basic factors in such a society are the heads of families possessing land of their own. They are entrusted with the care of all others, who do not own land and therefore are at risk in economic, social or moral terms (Levites, widows, orphans, guest workers, and indentured servants). The forms of assistance are also described: donating food, providing interest-free loans, cattle, land, and goods, providing hospitality. The law also ordains that the well-off must treat those who are in a disadvantaged material situation fairly. It should be particularly stressed that "the Israelite charity ethics comprised a fairly broad spectrum of norms, which specified a range of institutionalized practices" (Bird, 1982: 146). The responsibility for keeping the Law falls not only on separate individuals but on the whole Israelite community. God expects from His chosen people to have a just public order based on His commandments. The people fear God's wrath, because they believe that, for their transgressions, they may be punished with a bad harvest or other calamities (Bird, 1982: 146).

The Judaic civilizational code implies solidarity, which resembles the kind of relations that exist in a rural community or a large clan. The important difference is that this solidarity extends not to a relatively small territorial or kinship community, but over a whole ethno-religious group. And this is achieved without the integrating and subordinating function of the state. Two other important, and interconnected, characteristics of the Judaic code are that, firstly, the religious doctrine itself contains a clear and detailed conception of social order, offering an ideal for a perfect and harmonious society; secondly, as a direct corollary of the first, the holy book contains detailed instructions regulating social relations, such as the categories of persons, their rights and obligations, presented not abstractly but as concrete cases and ritual practices, a 
specific social cyclical order is established, etc.

The peculiarity of the Judaic code is especially salient when compared with the Christian civilizational code as expressed in the Gospels (the New Testament). An article by Frederick Bird (1982) contains a particularly valuable identification of the disparity between the two codes.

The Gospel narratives reveal a very different attitude towards social reality. Obviously, the motifs of wealth and poverty, of masters and servants, hold a large and important place in the Gospels. They contain criticism of the thirst for wealth and power, but no elaborated idea about how human society should be organized. There is a very clear reason for this lack: the disciples and followers of Christ believed that the days of man's perishable existence on earth were numbered, and that the Kingdom of God would soon come. This faith made it pointless to plan a perfect, but nevertheless human, order on earth. Until this eternal kingdom is established, the Gospels assume the Mosaic law to be valid, but see in the person of Christ "the decisive arbiter of its meaning" (Beed and Beed, 2015: 326).

The Christian civilizational code proper is characterized by a high degree of abstractness. The early Christians lived in expectation of the certain and imminent coming of Christ. That is why "the Christian moral standards necessarily assumed a teleological character" (Bird, 1982: 155156). The aim of a Christian life is to prepare the believer for this sacred future. The Divine Judgment, salvation or hell, are relevant for every individual but not for the community. Hence, the moral ideal is markedly personal, although it certainly influences the life of the community.

Christian ethics are built upon two fundamental commandments of Christ. The first and most important one is: "You shall love the Lord your God with all your heart, and with all your soul, and with all your mind." The second says: "You shall love your neighbor as yourself" (Matt, 22: 37-39). According to Bird, a third principle is added, which helps interpret the first two: evil does not lie in wealth as such but "in a too great attachment to material goods and wealth" (Matt, 22: 37-39). Primitive Christians rarely referred to the old Judaic social norms, although they observed some of them, such as the duty of providing hospitality, making private donations, offering interest-free loans. The 
commandment to assist one's neighbor "was not spelled out in a series of norms dictating specific actions either in relation to particular categories of needy persons or in relation to institutionalized means for collecting donations". In any case, Christ's commandments had priority over the Israelite norms ((Matt, 22: 156, 157). Hussain (2009: 132-133) asserts that the two basic commandments were not new ideas and were already contained in the Torah. But in Judaism, these commandments did not push into the background an elaborate social program and its corresponding detailed rules of relations.

With their specific emphasis, the two main commandments of Christ respectively determined two forms of Christian ethics. The first is distinguished by its great strictness - it is "the heroic ethic of selfsacrificing devotion". This ethics is relevant primarily for Christ's disciples, who must be prepared to make any sacrifice in the name of their faith. They start out on Christ's path, and in order to do so, they sell all their property, give the money to the poor, and reject their family, in order to devote themselves entirely to their mission. The second form of Christian ethics is that of mutual assistance. It was not recommended for most Christians in a community to give up their property in favor of the needy, because they would thereby become economically dependent. The virtue that was in effect for them was to make donations and assist their fellow Christians. In fact, they follow the maxim that evil does not lie in owning wealth but in being overly attached to it (Bird, 1982: 159160).

Thus, the underlying Christian civilizational code of the Gospels is significantly different from the Judaic. It does not share the project of a good and just social organization and is focused instead on the abstract principles of individual conduct that point the way to individual salvation and eternal life. The detailed regulation of relationships in the community is also lacking.

Now I will examine another formative (civilizational) code - that contained in the Qur'an. The holy book of the Muslims was linked to a society in process of transformation from tribalism and nomadism to a state organization and a settled life (Bonner, 2005: 393). Moreover, the founder of Islam, the Prophet Muhammad, was not only the creator of a new religious teaching but also the founder of a large and powerful state. 
HSS, vol. V, no. 3 (2016): 95-116

In his person, he combined religious and secular leadership. Hence, the holy texts of Islam have none of that distanced attitude towards the organization and functioning of society, an attitude that is understandable for Christianity, given the fact that Christ and his disciples were rather victims of the existing order and not its founders. The sacred texts of Islam share the Judaic commitment to building a just society, but from the very start, the religious community of Islam was organized as a state.

Typical for the Islamic social code are numerous prescriptions regulating economic relations. All of these, however, are subordinated to the basic concept of circulation and purification of wealth. God has endowed people with various earthly goods. Just as God gives in a disinterested way, so too must the owner of wealth share it with the other members of the Muslim community. Every wealth contains a portion or share (haqq) that should not remain in its possessor. Only when shared is the wealth "purified" and made secure. In this sense, wealth should circulate constantly and in a correct way. Incorrect circulation occurs when interest is taken on loans and when circulation is limited only to the wealthy. Correct circulation of wealth is that which moves downwards - from God to people and from the rich to the poor (Bonner, 2005: 392, 398, 402-405).

In accordance with this basic idea, the Qur'an and other fundamental texts indicate the obligations of the faithful towards different categories of persons: relatives, widows and orphans, the needy, travelers, etc. Charity exists in two forms: as special taxation (zakat) and as voluntary donation (sadaqua). Donating is a basic virtue, and the refusal to donate is equal to godlessness (Bonner, 2005: 394-396, 398-402).

Hence, the Islamic religious code, similarly to the Judaic, but unlike the Christian, displays a high commitment to the ideal of a harmonious human society. This is evident in the general concept of circulation and purification of wealth and in many concrete rules. However, unlike the Judaic code, the state is involved here from the very start, turning the sharing of wealth into a fiscal obligation alongside the acts of voluntary donation. 


\section{Conclusion}

This analysis should have a continuation, which will show the importance of the discussed basic codes for social practices and for history.

Human history, I suppose, is shaped by two basic, interactive elements objective processes (natural, demographic, economic, political, and cultural) and the practices of subjects (individuals and groups). The practices are meant to control these processes, but this control is achievable only to a limited extent and can have partial success. When processes get out of control, crises take place in society, which lead to basic changes in the existing practices or to the emergence of new ones.

For their part, practices are characterized by a great variety of concrete goals of different subjects. At the same time, they are formatted by world views and basic codes. On the other hand, these views and codes do not function independently and isolated from one another; they interact, overlap, which leads either to mutual enhancement of their effects or to mutual weakening and neutralization. Also, the periods of crisis in history generate new world views, which, however, arise on the grounds of basic codes.

Within the limits of the present article, I cannot discuss the question as to how these interactions are effectuated and what their results are. As a preliminary note, I would say that formative codes, though arising in the initial period of a culture or civilization, exert a significant influence on its whole historical development. Other authors have hinted at such an influence (for instance: Bird, 1982: 165; Brown, 2002: 9). In any case, there is hardly any room here for strict and absolute determinism. The important thing is to show the actual role of basic codes, through facts and analysis.

\section{References}

Beed, C. and Cora Beed. (2015). "A Biblical Basis for Reducing Extreme Disparity in Property Ownership." Evangelical Review of Theology. 39. 4: 324342.

Bird, F. B. (1982). "A Comparative Study of the Work of Charity in Christianity and Judaism." The Journal of Religious Ethics. 10. 1: 144-169.

Bonner, M. (2005). "Poverty and Economics in the Qur'an." The Journal of Interdisciplinary History. 35. 3: 391-406.

Brown, P. (2002). Poverty and Leadership in the Later Roman Empire. Hanover and 
HSS, vol. V, no. 3 (2016): 95-116

London: University Press of New England.

Brown, P. (2005). "Remembering the Poor and the Aesthetic of Society." The Journal of Interdisciplinary History, 35. 3: 513-522.

Chandhoke, N. (2005). "The City Sans Merci." India International Centre Quarterly, 16. 2: 109-115.

Clark, E. (1994). "Social Welfare and Mutual Aid in the Medieval Countryside." Journal of British Studies, 33. 4: 381-406.

Ener, M. (2005). "Religious Prerogatives and Policing the Poor in Two Ottoman Contexts." The Journal of Interdisciplinary History, 35. 3: 501-511.

Florence, C. (2010). "The Money Making in Ancient China: A Literature Review Journey Through Ancient Texts." Journal of Business Ethics, 91, Suppl. 1: 17-35.

Handlin S., Johanna F. (1987). "Benevolent Societies: The Reshaping of Charity During the Late Ming and Early Ch'ing." The Journal of Asian Studies, 46. 2: 309-337.

Hussain, J. "Participating in Godlinesss: A Study of the Law Concerning the Socially Marginalized in the Torah." McMaster Journal of Theology and Ministry, 10 (2008-2009): 101-139.

Jodhka, S. S. and Ghanshyam Shah. (2010). "Comparative Contexts of Discrimination: Caste and Untouchability in South Asia." Economic and Political Weekly, 45. 48: 99-106.

Kaplan, S. L. (1986). "The Character and Implications of Strife among the Masters inside the Guilds of Eighteenth-Century Paris." Journal of Social History, 19. 4: 631-647.

Lanza, J. (2009). "Les veuves dans les corporations parisiennes au XVIII siècle." Revue d'histoire moderne et contemporaine, 56. 3: 92-122.

Lohfink, N. S. J. (1991). "Poverty in the Laws of the Ancient Near East and of the Bible." Theological Studies, 52: 34-50.

McIntosh, M. K. (2005). "Poverty, Charity, and Coercion in Elizabethan England." The Journal of Interdisciplinary History, 35. 3: 457-479.

Niman, M. I. (2011). "The Shanti Sena 'peace center' and the non-policing of an anarchist temporary autonomous zone: Rainbow Family peacekeeping strategies." Contemporary Justice Review, 14. 1: 65-76.

O'Neill, B. (1982). Structures for Non-Hierarchical Organizations. Department of Industrial Engineering and Management Sciences, Northwestern University, Evanston, Illinois. Discussion Paper No. 535.

Pullan, B. (2005). "Catholics, Protestants, and the Poor in Early Modern Europe." The Journal of Interdisciplinary History, 35. 3: 441-456.

Sahai, N. P. (2005). "Crafts in Eighteenth-Century Jodhpur: Questions of 
HSS, vol. V, no. 3 (2016): 95-116

Class, Caste and Community Identities." Journal of the Economic and Social History of the Orient, 48. 4: 524-551.

Singer, A. (2005). "Serving up Charity: The Ottoman Public Kitchen." The Journal of Interdisciplinary History, 35. 3: 481-500.

Vassil'ev, K. (1998). Istoki Kitayskoy Tsivilizatsii (Sources of Chinese Civilization). Moskva: Vostochnaya Literatura.

Walter, E. V. (1973). "Pauperism and Illth: An Archaeology of Social Policy." Sociological Analysis, 34. 4: 239-254.

Wjuniski, B. S., and R. G. Fernández. (2009). "The Athenian Economy in Light of the Welfare State: Karl Polanyi's Work in Perspective." Journal of Economic Issues, 43. 3: 587-606.

Woodard, C. (1962). "Reality and Social Reform: The Transition from LaissezFaire to the Welfare State." The Yale Law Journal, 72. 2: 286-328.

Woodburn, J. (1982). "Egalitarian Soceties." Man (N. S.), 17. 3: 431-451.

Woodburn, J. (1998). "Egalitarian Societies." Limited Wants, Unlimited Means: A

Reader on Hunter-Gatherer Economics and the Environment. Washington, D.C.: Island Press, 1-28.

\section{Biographical note}

Ivan Katzarski is a Doctor of Sciences, Professor at the Institute for the Study of Societies and Knowledge at the Bulgarian academy of Sciences; research areas - philosophical and social anthropology, inequality and power, historical transitions, totalitarian socialism and post-totalitarian societies; author of seven books, and more than 100 articles in Bulgarian, French, English, and Russian. Member of the Union of Scientists in Bulgaria. Member of the Specialised Science Council of Philosophy at the High Attestation Commission, Council of Ministers. 